\title{
Um 13 de maio antecipado: edições temáticas, atualidade e memória no circuito TRIP e TPM
}

Frederico de Mello Brandão Tavares

Doutor; Universidade Federal de Ouro Preto

fredtavares.ufop@gmail.com

\section{Resumo}

Em abril de 2014, as revistas brasileiras TRIP e TPM publicaram uma edição temática, sob o mesmo título base - "Ser negro/negra no Brasil é $f^{*} d a^{\prime}$, e estabeleceram um diálogo editorial a partir de um gancho temporal: o dia 13 de maio, quando se comemora a abolição da escravatura no país. Com um mês de antecedência e a partir de coberturas estruturadas por conteúdos específicos, em contato ou não, as publicações anteciparam o acontecimento, previsto, encerrando-o em uma "totalidade" de pautas, acionada por seções e provocadora de um circuito que, antes do "acontecer do acontecimento", atualizou-o como temática, indicando seus sentidos. Neste contexto, o presente artigo observa relações existentes em acionamentos acontecimentais no jornalismo, mesmo quando estes não partem de uma cobertura factual. Tendo como objeto as edições de TRIP e TPM indicadas, busca-se percorrer a transversalidade originada pela tematização das revistas e compreender as afetações e/ou "determinações" que nela aparecem.

\section{Palavras-chave}

Memória. Atualidade. Editoração. Revista TRIP. Revista TPM.

\section{Tramas editoriais e acontecimentos}

O professor de literatura comparada da Universidade de São Paulo (USP) Samuel Titan Junior, em ensaio publicado na edição de lançamento da revista cultural Serrote, editada pelo Instituto Moreira Sales, fomenta um interessante argumento: a existência de "vasos comunicantes" entre o livro e o periódico. Seu texto, O romance e a revista: As Memórias Póstumas de Brás Cubas na Revista Brasileira reflete sobre o trânsito entre questões editoriais e literárias na formulação do conhecido romance de Machado de Assis, 
publicado originalmente de forma seriada nesse importante periódico brasileiro do século XIX. Titan Junior reflete sobre o "romance de folhetim serializado" e como entre as Memórias e a Revista Brasileira havia "um jogo de espelhos" de aspectos gráficos e editoriais. Mas, mais do que isso, "[...] num efeito de mise-en-abîme, a figura de Brás Cubas com sua 'singular volubilidade' seria, entre outras coisas, a redução, a suma maliciosa e paródica dos colaboradores que a Revista Brasileira reunia a cada novo número." (TITAN JUNIOR, 2009, p. 147). Na escrita, pelo estilo, e nas pautas, pelos assuntos referenciados, o texto de Machado de Assis sugeriria, aponta o professor, a prática e a exposição de um gênero, num movimento que seria tanto cômico - ao brincar com a própria revista e seus autores quanto autorreflexivo - por problematizar explicitamente a narrativa a partir da história contada.

Esse desvelamento do texto pelo texto, ou de uma forma pelo conteúdo, realiza um caminho interessante: coloca em cena um processo dialético revelador de estruturas editoriais, de certas "totalidades" que habitam os processos de editoração. Não a "realidade" propriamente dita destes, sua produção, mas a maneira como ela se articula a partir de produtos. Nesse sentido, se temos a ponte "reveladora" e "articuladora" entre literatura e imprensa periódica no final do oitocentos a partir de um personagem, é possível dizer que o jornalismo, no cotidiano contemporâneo, também segue, em si mesmo, permeado por costuras derivadas de seus referentes. Nos mais distintos veículos, identidades editoriais e seus processos de estruturação estão tramados por elementos jornalísticos que "determinam" maneiras de ser de um periódico e, ao mesmo tempo, situam-se em um jogo com lógicas que são externas a ele, mas não menos constituintes de sua morfologia.

0 nó entre tais elementos e dinâmicas, muitas vezes, encontra-se nos acontecimentos. Estes podem ser vistos como uma espécie de detonadores/acionadores de unidades de sentido diversas, que compõem as realidades editoriais e articulam o movimento de suas totalidades, dando elas a ver.

Nessa ambiência, estes mesmos acontecimentos são incorporados pelos produtos jornalísticos, sendo transformados e, muitas vezes, atualizados. Berger e Tavares (2010), no exercício de categorização do acontecimento jornalístico, apontam para a predominância de dois modelos deste, agrupados segundo nomenclaturas diversas a partir de vários autores: os acontecimentos imprevistos e os acontecimentos previstos. Tavares (2009) e Benetti, Storch e Finatto Júnior (2011) também apontam para lógicas acontecimentais que permeiam a cobertura de certas temáticas pela imprensa, com destaque para o jornalismo 
de revista, indicando a temporalização como elemento de cobertura de temas amplos cotidianos, não exatamente ligados à ocorrência de um fato, mas aos tempos que o atravessam.

Sobre esta última "modalidade", chamamos atenção para um recente episódio no cenário das revistas jornalísticas nacionais. No mês de abril de 2014, as versões impressas das revistas TRIP (2014) e TPM (2014) publicaram uma edição temática, sob o mesmo título - "Ser negro/negra no Brasil é f*da", e estabeleceram um diálogo editorial a partir de um gancho temporal: o dia 13 de maio, quando se comemora a abolição da escravatura no país ${ }^{1}$. Com um mês de antecedência e a partir de uma cobertura estruturada por meio de conteúdos específicos, em contato ou não, as publicações anteciparam o acontecimento, previsto, encerrando-o em uma "totalidade" de pautas, acionadas por seções e provocadora de um circuito, um "círculo em si mesmo" que, antes do "acontecimento acontecer", atualizou-o como temática, jogando luz, principalmente, sobre a questão do racismo.

Assim, por um mesmo tema ou mote - o racismo -, ambas as revistas deram-se a ver e colocaram em cena, por um lado, um assunto e, por outro, uma lógica editorial. Nas partes que compõem o todo de uma só publicação, bem como nas partes que compõem o todo do conjunto formato pela reunião de ambas as edições, pode-se observar uma certa reciprocidade instaurada que confere, como num processo dialético, sentido e significado à cobertura e aos produtos (as revistas), indicando uma "totalidade". Longe de adentrarmos na complexidade desse conceito ${ }^{2}$, mas partindo desse caso em específico, este artigo observa relações existentes em acionamentos acontecimentais no jornalismo, mesmo quando estes não partem de uma cobertura factual. Tendo como objeto as edições de TRIP e TPM supracitadas, busca-se percorrer a transversalidade originada pela tematização das revistas e, desse modo, compreender as afetações e/ou "determinações" que nela aparecem.

\section{Atualidade jornalística e transversalidade}

Franciscato (2001, p. 261) lembra que a atualidade jornalística pode ser pensada como uma das características que auxilia a “[...] singularizar o conteúdo produzido pelo jor-

\footnotetext{
1 TRIP e TPM, ambas publicadas pela TRIP Editora, lançam regularmente edições de mesma temática, tratando-a ora com repetição de textos nos dois títulos, ora com matérias específicas, enquadradas segundo as seções e o viés de cada revista (uma voltada para o público masculino e outra para o feminino).

2 A elaboração sobre o conceito de totalidade possui grande carga filosófica, não sendo intenção deste artigo realizar tal discussão. Para o momento, traremos referências que ajudarão a orientar o argumento do texto, respeitando, pois, os preceitos epistemológicos que as sustentam e colocando-os em face a autores contemporâneos.
} 
nalismo dos demais saberes sociais [...]". Para o autor, mesmo que sob um viés limitado, a apropriação desta dimensão [a atualidade] pelo jornalismo

[...] introduz a percepção de que este âmbito de problematização está também ligado às expectativas, interesses e necessidades de uma coletividade sobre conteúdos que ela considera relevantes para obter um conhecimento superficial, mediado pelo discurso jornalístico [...]. (FRANCISCATO, 2001, p. 261).

Em certa medida, menos que perguntar sobre o atual, problematizando-o, o jornalismo, por pressuposto, recorta e delimita um presente aparente, criando uma espessura temporal de referência, na qual se pode situar o cotidiano.

Em outro texto, que amplifica essa discussão, o autor (2005) aponta que o jornalismo está duplamente situado. Situa-se em contextos espaciais e temporais concretos - "[...] a instituição jornalística está entranhada no ambiente em que atua, o qual limita certas possibilidades de produção jornalística [...]” (p. 167)33. E possui vínculo com processos “[...] históricos que atravessam formas específicas de instituições e que constituem os princípios organizativos de uma sociedade, tais como a construção e a transmissão da cultura, as relações econômicas [...], as formas de ação política e as transformações tecnológicas [...]” (p. 167).

Antunes (2007), ao tentar desvelar os processos jornalísticos sob o viés da temporalidade, questiona como a narrativa jornalística, na "ansiedade" de falar de forma abreviada sobre o mundo, relatando tudo o que nele acontece, acaba por realizar uma cobertura previsível, que deixa de "perturbar" os acontecimentos naquilo que devem ser efetivamente "perturbados" (ou organizados pelo jornal).

Arguir a notícia pela temporalidade, indagar a relação entre acontecimento e experiência temporal afigura-se como uma forma de crítica e de olhar "externamente de dentro" a escrita jornalística, de reabri-la para desconhecer o conhecido. Assim procedendo, se pode avaliar a forma de construção da atualidade que os jornais hoje realizam (ANTUNES, 2007, p. 290).

Questionar a temporalidade jornalística, o que leva a pensar sua atualidade, cruza instâncias da ordem do conteúdo e da forma, do interesse público/do público e da maneira como as narrativas e coberturas são criadas. Nesse viés, a relação do jornalismo com o presente e, por consequência, com camadas de passado e futuro, abrange temáticas que recorrentemente retornam ao foco e tensionam o imaginário e a memória coletiva. Como

\footnotetext{
3 “É um ambiente que configura relações e práticas sociais tanto externas à instituição (desempenho de papéis sociais instituídos e relações de poder na construção de sentidos e ações sociais) quanto internas a ela (princípios organizativos da instituição, tais como regras, metas, conflitos, pressões, imposições, disputas)." (FRANCISCATO, 2005, p. 167).
} 
lembra Silverstone (2002, p. 234), "nossa mídia, tanto intencionalmente como à revelia, é instrumento para a articulação da memória." (SILVERSTONE, 2002, p. 234) 4 .

Zelizer (2008) reflete sobre essa relação que envolve a temporalidade no/do jornalismo e coloca a memória como uma espécie de dispositivo, que ajuda a olhar essa questão por um eixo tensionador:

Quando a forma convida a memória, o jornalismo usa o passado de modo a envolvê-lo com o presente. Mesmo que isso não seja necessário ou central para a cobertura jornalística que se realiza, o jornalismo, neste caso, produz uma variedade de formas jornalísticas que permitem que passado e presente encontrem-se simultaneamente discutidos em um mesmo relato. Incluiriam-se neste contexto analogias históricas, comparações diretas entre o presente e o passado, e investigações de eventos aparentemente "históricos". (ZELIZER, 2008, p. 83-84, tradução nossa)5.

Nesse viés, seja em matérias pontuais no interior de um veículo, seja em edições especiais de distintos produtos, é possível afirmar que o jornalismo cria uma série de sentidos sobre assuntos e fatos, propondo relações de atualização que entrecruzam temporalidades diversas no atravessamento da cobertura de um acontecimento ou na tematização deste, com destaque para suas facetas "de passado" e seu contínuo voltar. Como salienta Barbosa (2012, p. 153),

[...] o passado só existe como representação mental a partir do olhar individual daquele que o descortina. Portanto, o passado não é fixo: é materializado pelas recordações e sempre transformado pela interpretação. Assim, como o passado não é fixo, também o presente não é apenas um instante pontual. 0 presente indica o que vivemos, mas também as rememorações que o passado proporciona. Essas rememorações existem sempre no presente, construindo-o pelo entrelaçamento do mesmo (as ações vividas no presente) e do outro (as rememorações que tornam o passado presente).

No momento em que o passado se torna objeto jornalístico, tal qual acontece em datas comemorativas ou em situações que apontam para enquadramentos que contextualizem o acontecido por aproximação a eventos que lhe foram, historicamente, "semelhantes", ocorre uma espécie de evocação temporal que não apenas traz à tona o acontecido, mas o redescobre, o reconstrói, o reinventa. Nisso, mais do que apenas situar um

\footnotetext{
4 "Estudar a relação da mídia com a memória não é negar a autoridade do evento que é o foco da recordação, mas insistir na capacidade da mídia de construir um passado público, assim como um passado para o público. A textura da memória se entrelaça com a textura da experiência." (SILVERSTONE, 2002, p. 237).

${ }^{5}$ Do original: "When form invites memory, journalism uses the past so as to engage with the present. Neither necessary nor central to the journalistic coverage that ensues, journalism in this instance produces a variety of journalistic forms that allow for the present and past to be discussed in some kind of simultaneous relay. Included here would be historical analogues, direct comparisons between present and past, and investigations of seemingly "historical" events." (ZELIZER, 2008, p. 83-84).
} 
episódio no tempo e no espaço, o jornalismo passa a dar "relevância pública" a ele (FRANCISCATO, 2001), apoiando-se em uma intersubjetividade que se liga a uma atualidade, tornada evidente nesse processo (CHARAUDEAU, 2006). Como explica Barbosa (2003, p. 147), "o passado, convocado para intensificar o presente, passa a ser elemento de identificação para todos que participam do mesmo gesto comemorativo e instaura-se como prenúncio do futuro".

França (2011, p. 66), apoiado em Wertsch (2002), afirma que “[...] a memória é sempre baseada no presente [...]", o que permite que um veículo mude sua própria memória editorial de acordo com sua realidade atual. A memória, afirma o autor, “[...] seria muito mais uma forma de organização (ou reconstrução) de pedaços de informação dentro de um esquema geral do que uma lembrança acurada de pedaços isolados específicos dos acontecimentos [...]" (FRANÇA, 2011, p. 66).

Quando se trata de edições especiais e ou temáticas de um veículo, nas quais buscase esgotar um assunto ao longo de seções e pautas que operam de forma a fragmentar um assunto e, no conjunto, apontar para o seu todo espaço-temporal, esse tipo de "lógica da memória" é extremamente aparente. A "intensificação do presente" por meio do passado, nos dizeres de Barbosa (2003), coloca em tensão dois "todos", o do assunto e o do próprio veículo - uma espécie de instituição produtora e acionadora de memórias, como vai afirmar França (2011). E nesse jogo de totalidades ensejadas pela atualização jornalística, hierarquizações da sociedade e do jornalismo aparecem na estruturação do fenômeno que se coloca, tranversalizando-o.

Olhar para este cenário do ponto de vista da totalidade traz implicações e cuidados. Sabendo-se, por exemplo, que um dos lugares de maior discussão deste conceito reside na tradição de estudos marxista, há de se ter em mente que sua apropriação em outra área ou para fins "analíticos" não pode, em alguma medida, degenerá-lo. Isso significa, na visão de Kosik (2010), a observância da dialética como elemento central que permeia toda a sua constituição. 0 que, diz o autor, leva à necessidade de não se tomar como máxima a ideia de que "tudo está em conexão com tudo" ou de que "tudo é mais do que as partes".

A compreensão dialética da totalidade significa não só que as partes se encontram em relação de interna interação e conexão entre si e com o todo, mas também que o todo não pode ser petrificado na abstração situada por cima das partes, visto que o todo se cria a si mesmo na interação das partes. (KOSIK, 2010, p. 50, destaque do autor). 
Transpondo o conceito para o âmbito jornalístico, quando uma temática específica e complexa, a do racismo, é atualizada, as partes de seu todo, os conteúdos eleitos e a construção destes por uma publicação, assumem uma transversalidade que cruza temporalidades - tanto em relação ao conteúdo em si quanto em relação à periodicidade do periódico e a maneira como esta afeta sua produção e estrutura. A atualização de um mesmo tema a partir de arranjos editoriais recíprocos gera um feixe de relações cujo circuito faz oscilar pontos de vista e fragmentos, promovendo um jogo de luz e sombra sobre a informação criada, bem como sobre o imaginário sobre a temática em cena e a dialética do concreto e abstrato que o constituem.

Nesse universo, se olhamos o jornalismo "de revista", três dinâmicas que permeiam o jornalismo em geral - 1) um pertencimento ao presente (atentando-se, sob o viés da atualidade, às tramas da vida social), 2) na construção de um conhecimento sobre o mundo (atuando de forma hermenêutica sobre ele) e 3) no atendimento de certas necessidades informativas da sociedade, atualizando, ao mesmo tempo, padrões informativos - passam a estar particularizadas (TAVARES, 2011). A edição 231 da revista TRIP e a edição 141 da revista $T P M$, além de incorporarem essa singularização, criando um circuito que vale para pensar sobre elas próprias, encerradas nas próprias edições de abril de 2014, e no conjunto das suas centenas de edições prévias, sua identidade editorial (TAVARES, 2013), promovem um diálogo entre si, criando um terceiro circuito, que entrecruza atualidades a partir de um viés que congrega semelhanças e diferenças. Juntas, criam um acontecimento discursivo (PÊCHEUX, 1990) cujo resultado é uma tentativa de totalidade 6 .

Para Pêcheux, um acontecimento "[...] é um ponto de encontro entre uma atualidade e uma memória [...]” (PÊCHEUX, 1990, p. 17), ou seja, “[...] pode ser analisado como uma correlação entre o fato e a forma como o fato foi percebido e circulado, como ele se atualiza e se mantém sempre presente na memória coletiva [...]" (RASSI, 2012, p. 45). Nas revistas e suas respectivas edições aqui problematizadas, o gancho jornalístico que permite a antecipação do acontecimento transforma este em temática (histórica, que perdura; e contemporânea, que se atualiza) e, consequentemente, em um novo acontecimento. A complementaridade de suas capas, a partir de suas manchetes principais, deixa isso à mostra:

\footnotetext{
${ }^{6}$ Como lembra Veyne (1998) ao discorrer sobre o fato histórico, toda descrição é seletiva, sendo o fato um "cruzamento de itinerários possíveis" (VEYNE, 1998, p. 45) e não uma unidade natural. Sobre esse processo, ver a reflexão de Rassi (2012).
} 
Figuras 1 e 2 - Revista TRIP no 231, abril de 2014, edição com capa dupla
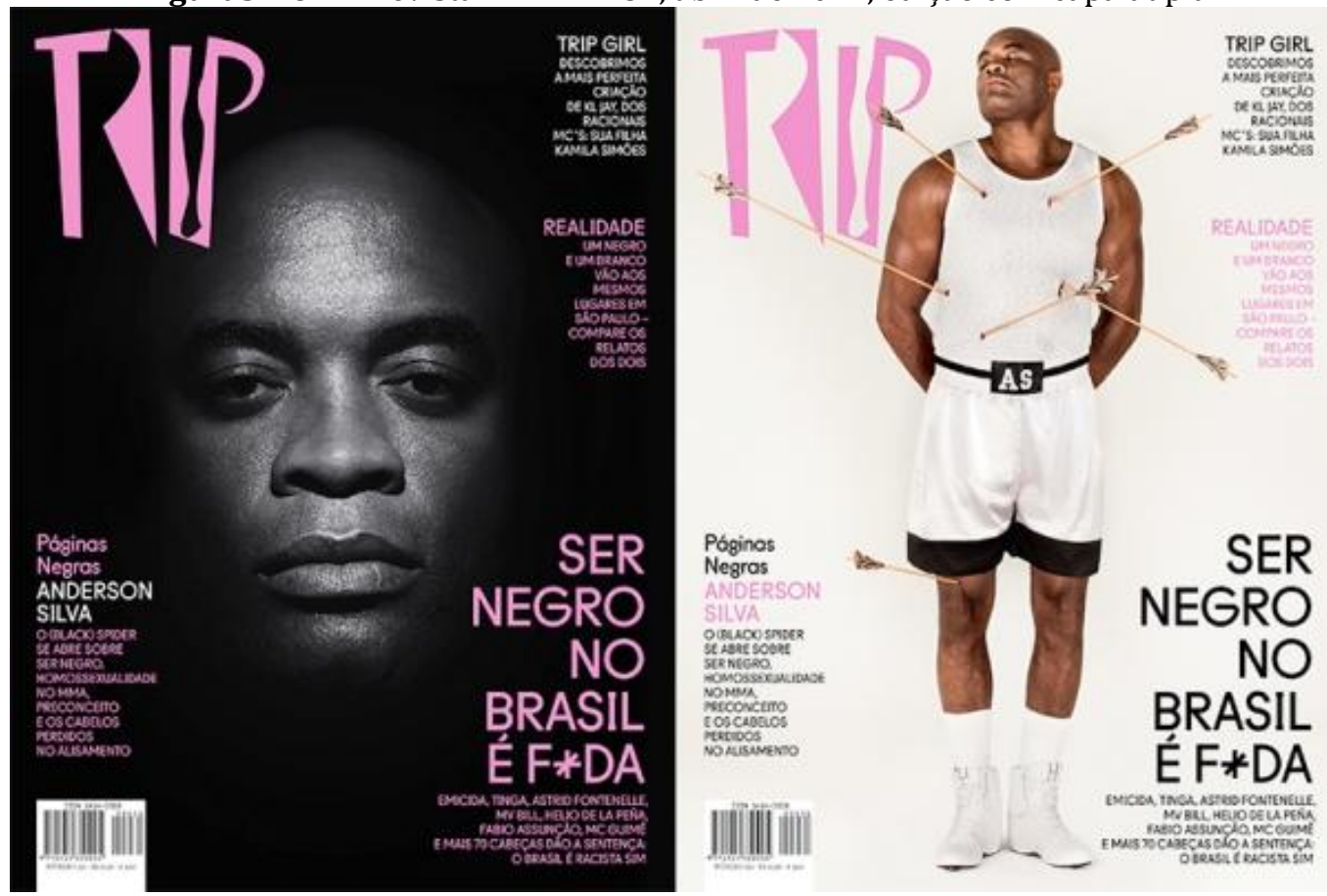

Fonte: Revista TRIP (2014).

Figuras 3 e 4 - Revista TPM no 141, abril de 2014, edição com capa dupla

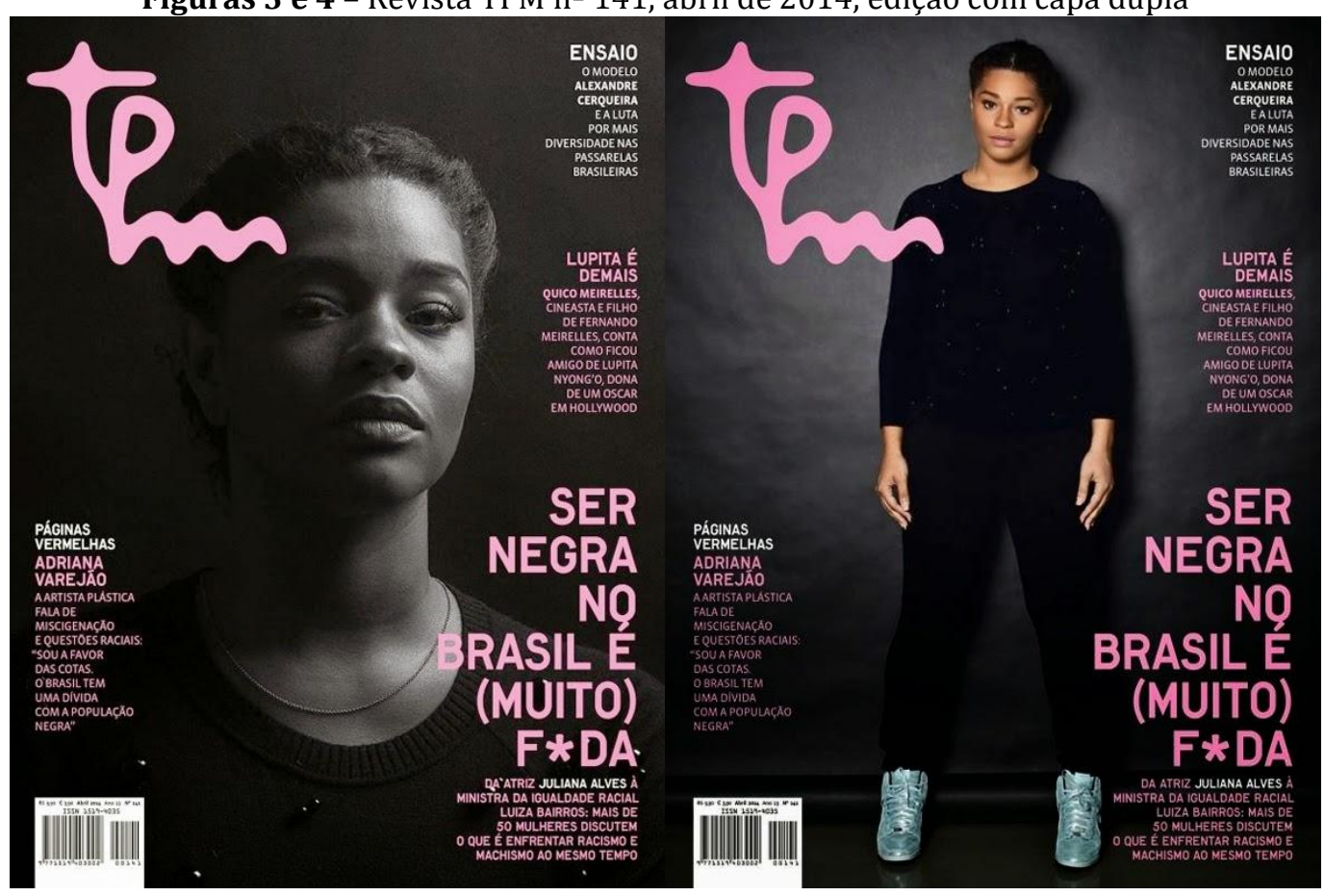

Fonte: Revista TPM (2014). 
Os dizeres "Ser negro no Brasil é fo*da" (TRIP) e "Ser negra no Brasil é (muito) f*da" (TPM) explicitam uma opção editorial partilhada - lembrando que ambas as revistas são editadas pela mesma editora - e encadeiam, na escolha discursiva de atualização, uma série de formações discursivas preexistentes, levando à criação de um outro acontecer. 0 uso de uma expressão popular - "é foda" -, funcionando como figura de linguagem para expressar a temática, assim como sua marcação de intensidade pela questão do gênero, aponta para o "gesto de autor" e cria uma trama de enunciado e enunciação, de hierarquias e identificações.

Somam-se a isso referências outras, de âmbito editorial e social, que habitam a memória coletiva (HALBWACHS, 1990). Ao trazer o racismo como protagonista de sua cobertura, as revistas acionam ícones imagéticos do passado e tanto falam do acontecimento porvir - o aniversário da abolição da escravatura no Brasil - quanto do negro como sujeito na sociedade e da revista como sujeito jornalístico.

A foto de busto da atriz Juliana Alves (Figura 3) e todo seu conjunto semiótico (luz, olhar da personagem, cores) remetem a fotografias de escravas negras do século XIX e a representação mista/contraditória de sua beleza/seriedade/dor, na tipificação-síntese buscada por aqueles retratos7 (HIRSZMAN, 2011). Já a capa com a imagem de Anderson Silva "flechado" (Figura 2) remete não apenas à iconografia religiosa (Figura 6), na pintura de São Sebastião (Andrea Mantegna, 1480), mas também à clássica e famosa capa da revista estadunidense Esquire, na edição de abril de 1968, que trouxe no centro, fotografado, o boxeador Muhammadi Ali, com expressão de dor, agonizante pelas setas que ferem seu corpo, no auge da carreira (Figura 5) ${ }^{9}$. A capa em questão não possuía manchetes, mas tornou-se icônica por tudo que nela faz convergir em relação à época de sua circulação e aos contextos que a constituíam (Guerra do Vietnã e um momento de fortes conflitos raciais nos EUA). Exatos 48 anos depois, este passado - de negro, lutador, celebridade - se atualiza em TRIP e cria um acontecimento de ordem editorial e ao mesmo tempo jornalística.

\footnotetext{
7 Ver: ERMAKOFF, George. 0 negro na fotografia brasileira do século XIX. Rio de Janeiro: G. Ermakoff Casa Editorial, 2004. E AZEVEDO, Paulo Cesar de; LISSOVSKY, Mauricio (Orgs.). Escravos brasileiros do século XIX na fotografia de Christiano Jr. São Paulo: Ex Libris, 1988.

8 A capa é criação do publicitário nova-iorquino George Lois, que, entre 1962 e 1972, foi o responsável por capas históricas da revista Esquire. A capa em questão, à qual remete TRIP, circulou em 1968, um ano após Muhammad Ali, então campeão mundial de boxe, ter se recusado a alistar-se no exército dos Estados Unidos, alegando motivos religiosos. 0 lutador havia se convertido ao islamismo, o que o levara, inclusive, a deixar de usar o nome de nascimento, "Cassius Marcellus Clay Jr.". A recusa de 1967 fez com que um juiz federal o condenasse a cinco anos de prisão. Enquanto aguardava a decisão da Suprema Corte dos EUA, que o absolveu anos depois, Esquire, pelas mãos de George Lois (inspirado na pintura de São Sebastião), estampou o lutador em sua capa, criando uma espécie de "cartaz" que se tornou referência imagética (midiática e social).

9 A aproximação entre essas imagens também está presente no blog “DesignArt” (DESIGNART..., 2012).
} 
Figura 5 - Capa da Revista Esquire, abril de 1968

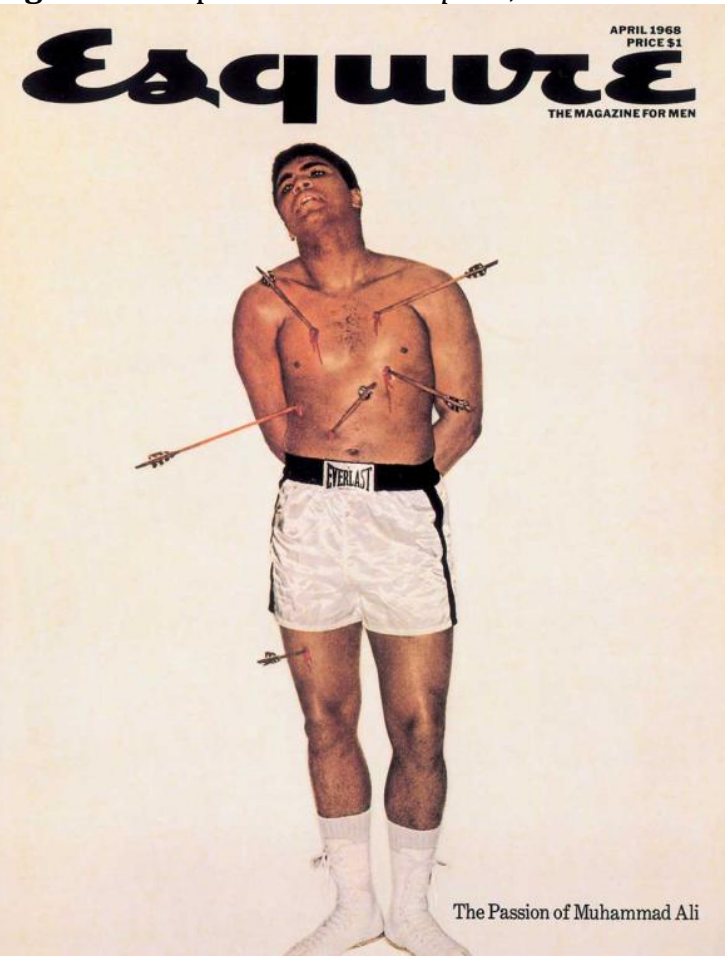

Fonte: DesignArt Blog (2012)
Figura 6 - São Sebastião (Mantegna, 1480)

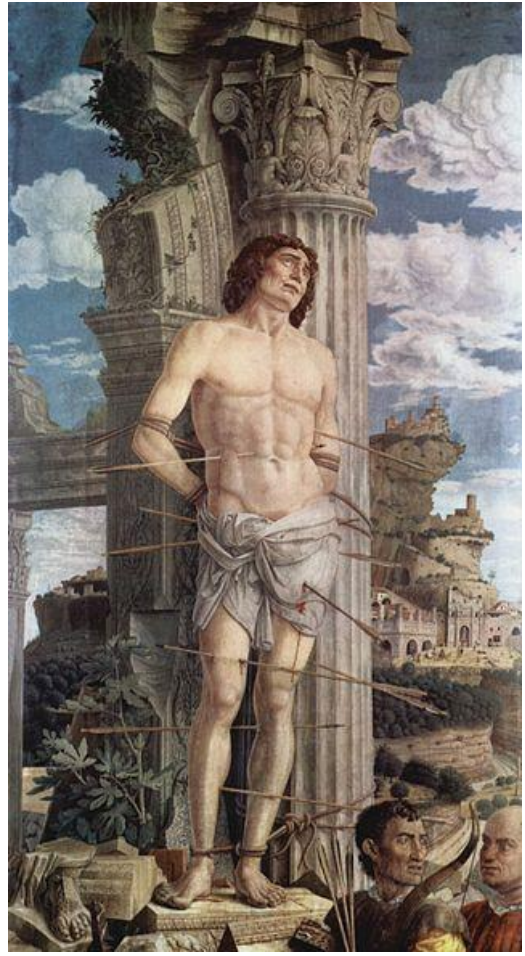

Fonte: DesignArt Blog (2012)

Como sintetiza França (2011, p. 92):

[...] as diferentes informações que surgem no jornalismo criam conceitos que, longe de produzirem um conhecimento único, levam a um sentido produzido por fontes diversas e em constante embate. São representações que deslizam de acordo com as relações que estabelecem com outras representações, definindo-se de uma forma de tal modo mutável e aberta ao contexto em que se produz que só podem ser compreendidas como memória social.

Assim, o circuito TRIP-TPM, como acontecimento, pelos recursos plásticos de seu entorno, bem como ao enquadre editorial que lhe marca, promove uma ruptura do sentido sobre o tema - e detona, de maneira entrecruzada, um processo de encadeamento de atualizações que se expande pelo interior das revistas (edições) e pelos fios que as conectam. 0 que pode ser identificado nas seções dos periódicos e na maneira discursiva como as pautas se concretizaram, nos editoriais das edições, e nas marcas outras, verbais ou não, que apontam para as costuras de um todo e sua transversalidade. 


\section{A antecipação do 13 de maio e seu acontecer}

Entre as quatro capas produzidas para o mês de abril de 2014, duas delas evidenciam muito claramente o diálogo proposto pelas revistas. Nelas, os personagens centrais - o lutador Anderson Silva e a atriz Juliana Alves - estão envolvidos por um fundo preto e seus rostos ganham iluminação específica ${ }^{10}$. 0 rosto de Anderson, na TRIP (Figura 1), bem no centro da página, parece surgir em meio a escuridão. Seu olhar é direto, centrípeto e centrífugo ao mesmo tempo. Seu semblante é sério e inquiridor. Há uma dureza na expressão, que dialoga com a figura do Anderson mártir, presente na outra capa de TRIP elaborada para a edição (Figura 2).

Na TPM (Figura 3), ocupa a cena central o rosto e parte do dorso de Juliana. Uma luz incide sobre sua face esquerda, à direita na página. Por isso, é seu olhar esquerdo que escapa à sombra, permanecendo o direito velado pela não iluminação. A atriz ainda veste uma blusa preta, a qual se avista na composição do jogo de cor elegido, que cria o movimento figurativo de leitura: do negro para o claro, para a "única" e relutante luz, que para cada personagem é distinta. Anderson desponta "por inteiro", Juliana permanece na penumbra. Na semelhança do negro - no primeiro plano (corpo) e no segundo plano (fundo e composição) - e na diferença da luz (iluminação), as relações sobre o tema vão sendo compostas e se atravessando; pela força imagética, pelo imaginário e seus contornos; o que "acontece" também nos Editoriais das edições e naquilo que os alinhava.

A primeira frase do editorial de TPM, que contempla todo um parágrafo, diz: 'Só existe uma coisa mais desafiadora do que ser negro no Brasil: ser negra" (TPM, 2014, p. 6). As palavras fazem alusão direta à manchete principal da revista e (se) explicam, mesmo que o leitor desconheça a edição da revista TRIP, sua diferença e complementaridade em relação a ela. No encerramento da primeira parte do editorial, a ideia exposta no início é sintetizada: "Resumindo, mulheres têm mais obstáculos a transpor do que os homens. Negros, por sua vez, mais do que brancos. Já mulheres negras costumam nascer diante de um Himalaia de desigualdades históricas." (TPM, 2014, p. 6). 0 argumento segue com considerações sobre as pautas $^{11}$ da edição, pontuando os personagens e assuntos a serem cobertos e tendo como

\footnotetext{
${ }^{10}$ Ambas as capas (Figura 1 e Figura 3) aparecem reproduzidas no interior das revistas, como anúncio de uma em outra, acompanhadas dos dizeres: "Já nas bancas".

${ }^{11}$ Chamamos a atenção para um exemplo: o perfil da mãe do cantor Emicida, uma senhora negra, assim definida por TPM: "Jacira Roque de Oliveira, mãe do rapper Emicida, nunca se conformou com a máxima de que 'preto e pobre não tem direito' e foi à luta para mudar a sua vida e a de seus quatro filhos". (TPM, 2014, p. 48). É essa a tônica que perpassa as matérias da edição, com pautas e ganchos que buscam fragmentos menos usuais para tratar do tema do racismo, como no caso de Emicida. Fala-se da mãe, mulher, mas tem-se o cantor, sua visibilidade (e politização), como ponto de partida para a pauta.
} 
mote a desconstrução do mito da igualdade racial e do fim da escravidão no país. Todo o texto está envolto em segundo plano (que também funciona como moldura ao texto) por diversas capas de TPM que, nas mais de 100 edições da revista, trouxeram celebridades negras brasileiras e internacionais fotografadas. Um indicativo da posição editorial da publicação, que remete a seu passado e, pelo presente, atualiza sua identidade, dizendo, indiretamente: somos uma revista igualitária. 0 que, inclusive, dá credibilidade e autoridade para eleger, numa edição especial, o racismo como tema.

Esse "passado editorial" é o mote que abre o editorial da revista TRIP, fazendo menção à temática edição do mês anterior, de março de 2014, e trazendo o gancho para a edição de abril:

\begin{abstract}
A TRIP do último mês trazia na capa, e em boa parte de suas páginas, uma pergunta direta: "Brasil - vai ficar ou tá pensando em ir embora?". Essa foi certamente uma das edições que geraram maior repercussão nos diversos fóruns de debates ao longo dos últimos anos da revista. Muito especialmente nas chamadas redes sociais. Tudo indica que conseguimos capturar e trazer para o andar térreo uma sensação incômoda e recorrente que andava pairando pesada sobre a cabeça de muita gente por aí. [...] Uma sensação de andar pra trás eternamente que acabou por ventilar novamente as conversas e reflexões sobre as possibilidades de partir para outros cenários em que ao menos as questões muito básicas já tenham sido minimamente equacionadas. [...] E o que seriam, afinal, essas tais questões básicas? Queremos falar sobre elas, estressá-las no limite, usar nossa energia para tirá-las do escuro (TRIP, 2014, p. 28).
\end{abstract}

O editorial começa com a menção temporal e termina com a menção temática, novamente usando uma figura de linguagem para dialogar com o assunto em foco: o racismo. Na página de fundo branco, há uma colagem verbal, composta por frases de personagens conhecidos, com depoimentos sobre "por que é foda ser negro no Brasil". Dizeres dos rappers MV Bill e Emicida, do jogador de futebol Tinga, e do cantor Simoninha, estampados nas cores marrom e preto, jogam luz sobre o editorial da revista, endereçando sua leitura. As capas de TRIP dialogam também: a capa negra, escura, com a capa branca, reluzente. A chamada principal e as secundárias criam um espelho para refletir um mesmo desconforto.

Assim como em TPM, o editorial de TRIP elenca de maneira dissertativa as pautas que constituirão a edição, explicando como a temática se subdivide em "temas de si mesma", e constrói, pela atualidade e autorreferencialidade, seu circuito transversal. 0 título do editorial, "Desculpe o português" (TRIP, 2014, p. 6), volta ao longo do texto, sintetizando o tema e apertando o nó da costura editorial proposta através de um trocadilho: “Com o 
perdão do meu português, (ou dos nossos portugueses como talvez me corrigisse o sociólogo), racismo é foda. Muito foda" (TRIP, 2014, p. 6).

Em ambos os editoriais, o gancho com a factualidade fica exposto. Três trechos comentam episódios do Brasil contemporâneo sobre a questão da negritude, seja de forma literal ou não. TPM resgata a novela "A Escrava Isaura", lembra de Lucélia Santos, a escrava branca, e relata o episódio próximo à época da publicação da edição, do flagra da atriz em um ônibus coletivo no Rio de Janeiro, exposto nas redes sociais e que ganhou repercussões conflitantes. TRIP faz menção a um acontecido, também no Rio: o corpo de uma mulher baleada numa ação policial foi posteriormente arrastado até a morte, pendurado pelas roupas, por um carro da Polícia Militar carioca. Além disso, o texto lembra de situação recente em um estádio brasileiro, quando o jogador Tinga, à época atleta do Cruzeiro, é chamado de macaco durante uma partida de futebol. Não à toa, há uma fala de Tinga em destaque na página do editorial e este personagem soma-se a outros, no interior da revista, em uma matéria (TRIP, 2014, p. 64), em que famosos e anônimos falam sobre situações de discriminação por eles vividas.

Esta matéria, na estrutura da TRIP, contempla a chancela da versal "Diversidade" que, junto a outros 11 termos, compõe, como diz a revista, os 12 temas "prioritários e essenciais que inspiram seus princípios": corpo, alimentação, trabalho, sono, teto, saber, liberdade, biosfera, conexão, diversidade, acolhimento, desprendimento. São eles que enredam as matérias sobre o racismo da edição de abril de 2014. No índice da edição (TRIP, 2014, p. 26), todos os destaques ligam-se por linhas pontilhadas e coloridas, que saem desses termos e de suas definições, presentes numa coluna à esquerda da página. As seis matérias principais, alinhavadas aos temas, são:

a) TRIP Girl: Filha de KL Jay, o DJ dos Racionais, Kamila Simões mostra que tem luz própria - e de sobra;

b) Existe Racismo no Brasil? - 0 rapper MV Bill, a antropóloga Lilia Schwarcz e a juíza Luislinda Valois respondem à questão;

c) Aconteceu comigo - 0 jogador Tinga, o humorista Helio de La Peña e a apresentadora Astrid Fontenelle relatam casos de racismo;

d) Eu e Lupita Nyong'o - Quico Meirelles conta como foi trabalhar com a vencedora do Oscar num set de filmagem no Quênia; 
e) Tem jeito? - O rapper Emicida, o escritor Paulo Lins e a ativista Sueli Carneiro discutem como combater o preconceito racial;

f) Teste de rua - Dois homens - um cineasta negro e um repórter branco - testam se existe preconceito em São Paulo.

Além das pontes com os 12 temas orientadores, percebe-se, pelas chamadas principais, como personagens e assuntos dos editoriais se cruzam e indicam como os nós, ao longo de toda a revista, vão se amarrando. Evidenciam, seja na "luminosidade" do ensaio de Kamila Simões ("Negra Gata"12), seja na (re)presença de MV Bill, Tinga e Emicida, os desdobramentos da temática, configurando partes para um todo. Além disso, deixam à mostra os desdobramentos da própria revista em outro jogo de fragmentos e totalidade, marcado pela interação verbal e visual que é tanto intrínseca à edição (presentes em seu espaço discursivo mais amplo) quanto àquilo que ela conecta externamente (tais quais os episódios narrados no editorial, mas não tratados na revista; ou na referenciação a outros periódicos, caso da capa inspirada em Esquire), formando diversos "todos".

O sumário/índice de TPM (2014, p. 8), apresenta-se a partir de 11 seções, sendo uma delas chamada "ESPECIAL RACISMO". No entanto, como se verifica nas demais chamadas, que explicam as pautas e que depois se desdobram em títulos no interior da revista, quase todos os assuntos tratados falam de temas referentes ao tema principal, principalmente aqueles que ocupam as seções nobres (entrevista, perfil, opinião, reportagem):

16 PÁGINAS VERMELHAS [Entrevista] - A artista plástica Adriana Varejão fala sobre o novo trabalho, que tem miscigenação como tema, além de fama, dinheiro, processo criativo e racismo. 28 BAZAR - Ocupação Zuzu Angel; as peças favoritas da atriz Erika Januza; um papo com Valter Hugo Mãe, moda brasileira inspirada na África. 38 ESPECIAL RACISMO - A atriz Juliana Alves, a cantora Ellen Oléria, a ministra Luiza Bairros, a miss Elisa Freitas, a ativista Sueli Carneiro, a consulesa Alexandra Loras, a modelo Samira Carvalho e outras mulheres discutem o racismo do ponto de vista feminino. 62 ENSAIO - Filho de uma brasileira com um africano, o modelo Alexandre Cerqueria luta por espaço nas passarelas de moda. 70 MODA Tênis que vão da rua para a festa na maior naturalidade. 80 SEMANA DE MODA - A funcionária do Google Christiane Silva Pinto mostra como se vestir bem e barato. 82 BELEZA - As dicas da atriz Mariana Nunes; kit para cuidar das unhas e das mãos; o teste dos autobronzeadores; a vez dos cabelos curtos. 87 BADULAQUE - Grandes mentiras da atualidade; manifesto "Morena não, negra sim"; lembranças do Mussum e da Tia Anastácia; da "nega do cabelo duro" à "nega do suvaco cabeludo"; a não

\footnotetext{
${ }^{12}$ Uma análise mais cuidadosa das nomeações utilizadas pelas revistas e das palavras em geral, que aparecem para falar do racismo, seria também um importante complemento à compreensão crítica das totalidades aqui apontadas. Por ora, apenas ressaltamos esse entendimento, não aprofundando a interpretação sob esse viés.
} 
entrevista com whey protein; cocar é fashion; em busca das bonecas negras. 95 RESPIRO - Maria Ribeiro; 96 COLUNA DO MEIO - Milly Lacombe. 98 PRA FECHAR - Maria Gabrilli.

Diferente de TRIP, que apenas coloca no índice o conteúdo referente ao tema especial da edição, TPM elenca os demais assuntos abordados, apontando, já nesta parte indicativa da edição, como, internamente, em si mesma, os temas se atravessam. A temática do racismo ultrapassa as seções específicas a ele destinadas e tangencia outras, do começo ao fim da revista. Entretanto, se olhamos as seções mais destacadas, ambas as revistas priorizam o racismo como tema, caso das entrevistas principais (seção "Páginas Negras" de TRIP e "Páginas Vermelhas" de TPM), com o personagem da capa, Anderson Silva em TRIP e com a artista plástica Adriana Varejão, em $T P M^{13}$.

As estruturas de TRIP e TPM dialogam e criam uma coerência própria, que busca olhar para o tema por outros ângulos, mas de acordo com dois pontos de vista editoriais: o da própria publicação - como tal periódico olha para o mundo - e o do seu próprio nicho para quem o periódico se destina. Pode-se dizer que há em TRIP e em TPM uma unidade na diversidade que, apesar de não se esgotar e restringir-se às possibilidades de cobertura de um todo temático enviesado, deixam ver esse(s) todo(s), as estruturas e determinações que transpõem e cruzam aspectos da editoração jornalística e do tempo social brasileiro.

Ao trazer a temática do racismo, ambas as revistas atualizam (pelo gancho temporal) e antecipam o tema, preparando o sentido para o acontecimento que virá, no mês seguinte, enquadrando o acontecer antes de ser. Um porvir.

\section{Racismo e editoração: fim sem começo, começo sem fim}

Em 2014, a abolição da escravatura no Brasil completou 126 anos. 013 de maio (data comemorativa para o episódio), se observado na duração histórica que lhe marca, pode ser afirmado como inserido, tal qual nos jogos característicos da memória, num contexto de esquecimento e rememoração que possui importante papel nos sentidos que são sobre ele criados. A narrativa centenária do mito da democracia racial, por exemplo, acompanhada dos muitos discursos sobre a identidade do país, não foge a essa lógica,

\footnotetext{
${ }^{13}$ Adriana Varejão também aparece na seção "Salada”, em TRIP (2014, p. 40). Uma nota fala de uma nova exposição da artista, com início previsto para 5 de abril de 2014, em São Paulo. 0 final do texto explicita o circuito das revistas, recuperando um trecho da entrevista de Varejão para TPM (2014): “'Esses nomes são uma maneira de disfarçar uma identidade que é negra. Falar 'um pouco claro' ou 'queimada de praia' é um modo de negociar essa questão, de não dizer que é negro. Por outro lado, existe essa total impossibilidade de determinar cores de pele. Cada indivíduo tem uma cor diferente, a tentativa de classificar vai ser sempre inútil', diz a artista, entrevistada em Páginas Vermelhas da Tpm deste mês".
} 
criando certas "verdades" ou naturalizações e atuando sobre a lembrança e a apreensão a respeito de questões históricas e cotidianas que fogem ao testemunho, mas que se tornam correntes pela mediação autorizada ou ordenada de algumas vozes e atores sociais. Assim, a afirmação mitológica de uma "democracia racial" no cotidiano nacional, por exemplo,

[...] encobre os conflitos raciais, possibilitando a todos se reconhecerem como brasileiros e afastando das comunidades subalternas a tomada de consciência de suas características culturais que teriam contribuído na construção e na expressão de uma identidade própria. Essas características são "expropriadas", "dominadas", "convertidas" em símbolos nacionais pelas elites dirigentes (MUNANGA, 1996, 185).

A pesquisadora e antropóloga Lilia Schwarcz (1996, p. 29), ao tratar das relações raciais no Brasil, lembra a relação destas com o nosso tempo e imaginário, problematizando as maneiras como hierarquizamos e assumimos suas distintas formas:

A história ajuda a lembrar que não basta exorcizar o passado, e que todos nós somos o resultado de uma história particular, cujas marcas não estão em nossos corpos, como as sevícias escravas, mas se inserem em hábitos pouco compreendidos em sociabilidades distintas.

Segundo Schwarcz (1996), no Brasil o preconceito e a discriminação existem, mas são sempre atributos do "outro": o brasileiro (indivíduo) se sente uma "ilha de democracia racial" cercado de racistas por todos os lados. Utilizando-se de duas expressões, a autora diz que há no Brasil 1) um preconceito de ter preconceito ("feliz expressão cunhada por Florestan Fernandes") e que aqui 2) se pratica um "racismo cordial": o sujeito se mostra amável (para fora) mas, na prática, reproduz hierarquias cristalizadas e intocadas. "0 racismo no Brasil é vivido, mais do que afirmado, o que torna difícil a própria definição do termo preconceito no contexto brasileiro" (SCHWARCZ, 1996, p. 176). O racismo se manifesta na ação invisível e naturalizada do cotidiano.

Pode-se dizer que é dessa leitura que partem as revistas TRIP e TPM. Tomam para si as "verdades" sobre o racismo, mostrando sobre ele uma compreensão como ponto de partida - um todo vislumbrado -, fragmentando-a para uma leitura que se pretende questionadora/problematizadora.

Na seção "Badulaque" de TPM (2014, p. 87), por exemplo, um conjunto de cinco entre sete textos fala de maneira ora irônica, ora humorada, sobre a temática do racismo; e um sexto texto também trata da questão das diferenças, abordando a temática indígena a partir do povo Guarani-Kaiowá. Na primeira coluna, sob a versal "Grandes mentiras da atualidade" (TPM, 2014, p. 87), a manchete principal diz, em tom de ironia: "Não existe 
racismo e não era publipost". A coluna seguinte (TPM, 2014, p. 88), de versal "Manifesto", segue com a seguinte chamada: "Morena? Não, negra!". A terceira coluna, na página seguinte (TPM, 2014, p. 89), sob a versal "Malditos anos 70 e 80", intitula-se: "Éramos crianças racistas" e remete a personagens do imaginário infantil televisivo da época: Tião Macalé, Vera Verão, Tia Anastácia, Mussum e Mammy (a empregada de E o vento levou). Na coluna seguinte, "Tudo pode piorar" (TPM, 2014, p. 90), o título do texto é: "Da 'nega do cabelo duro' à 'nega do suvaco cabeludo'”. A autora (Nina Lemos) critica um humorista "internauta" brasileiro (Pranchana Jack) e sua nova versão para a conhecida música "Nega do cabelo duro", hit do carnaval baiano nos anos 1970 e 1980. Um último texto, na coluna "Mundo infantil" (TPM, 2014, p. 92) toca em um tema delicado - a invisibilidade/ausência de bonecas negras - e ainda faz menção ao circuito existente entre TRIP e TPM: "Já que o tema da Trip e da Tpm é racismo, resolvemos investigar o número de bonecas negras à venda no Brasil e caímos duras. Sabíamos que neste país de gente jovem reunida com toda a mistura do mundo as bonecas mais 'bonitas' são as louras. Ok. Mas vamos aos números”. No olho da matéria, o dado já diz: apenas $10 \%$ das bonecas vendidas no país são negras.

As colunas de encerramento da edição de TRIP seguem essa mesma perspectiva. Precedidos por uma grande reportagem - "Existe preconceito de cor no Brasil ainda?" (TRIP, 2014, p. 90) -, os textos "Racista em mim", de Henrique Goldman (TRIP, 2014, p. 96), "Black Power", de André Caramuru Aubert (TRIP, 2014, p. 97), "Retrato de um país doente", de Alê Youssef (TRIP, 2014, p. 98), "Matilde e Balbino", de Luiz Alberto Mendes (TRIP, 2014, p. 100), "Diversidade Já", de Ronaldo Lemos (TRIP, 2014, p. 104) e "Sem limites", de Ricardo Guimarães (TRIP, 2014, p. 106) traçam um panorama presente do racismo no dia-a-dia brasileiro, utilizando-se de ícones históricos da cultura pop/indústria cultural para tratar de preconceito e intolerância. Criam, em conjunto, uma espécie de mapa sobre as temáticas abordadas na edição, amarrando-as pelo viés da memória, um relembrar que dialoga tanto com o imaginário coletivo quanto com a comum autorreferencialidade midiática. Não apenas pelos produtos evocados (muitos cartazes de filmes e séries), mas também pelo próprio cenário da revista impressa e seu posicionamento.

A reportagem "Existe preconceito de cor no Brasil ainda?" (TRIP, 2014, p. 90) é uma espécie de remake "problematizador" de outra grande reportagem, de (quase) o mesmo título - apenas sem a palavra "ainda" e sem o ponto de interrogação, que indicava a afirmação no título - publicada pela extinta revista Realidade em 1967. A abertura da matéria de TRIP situa esse movimento: "Uma reportagem da icônica revista Realidade 
mostrava em 1967, como um negro e um branco eram tratados ao passar pelas mesmas situações. Cinco décadas depois, a TRIP se inspira na experiência para investigar: será que alguma coisa mudou?" (2014, p. 91).

Figura 7 - Capa da Revista Realidade nํ19, outubro de 1967
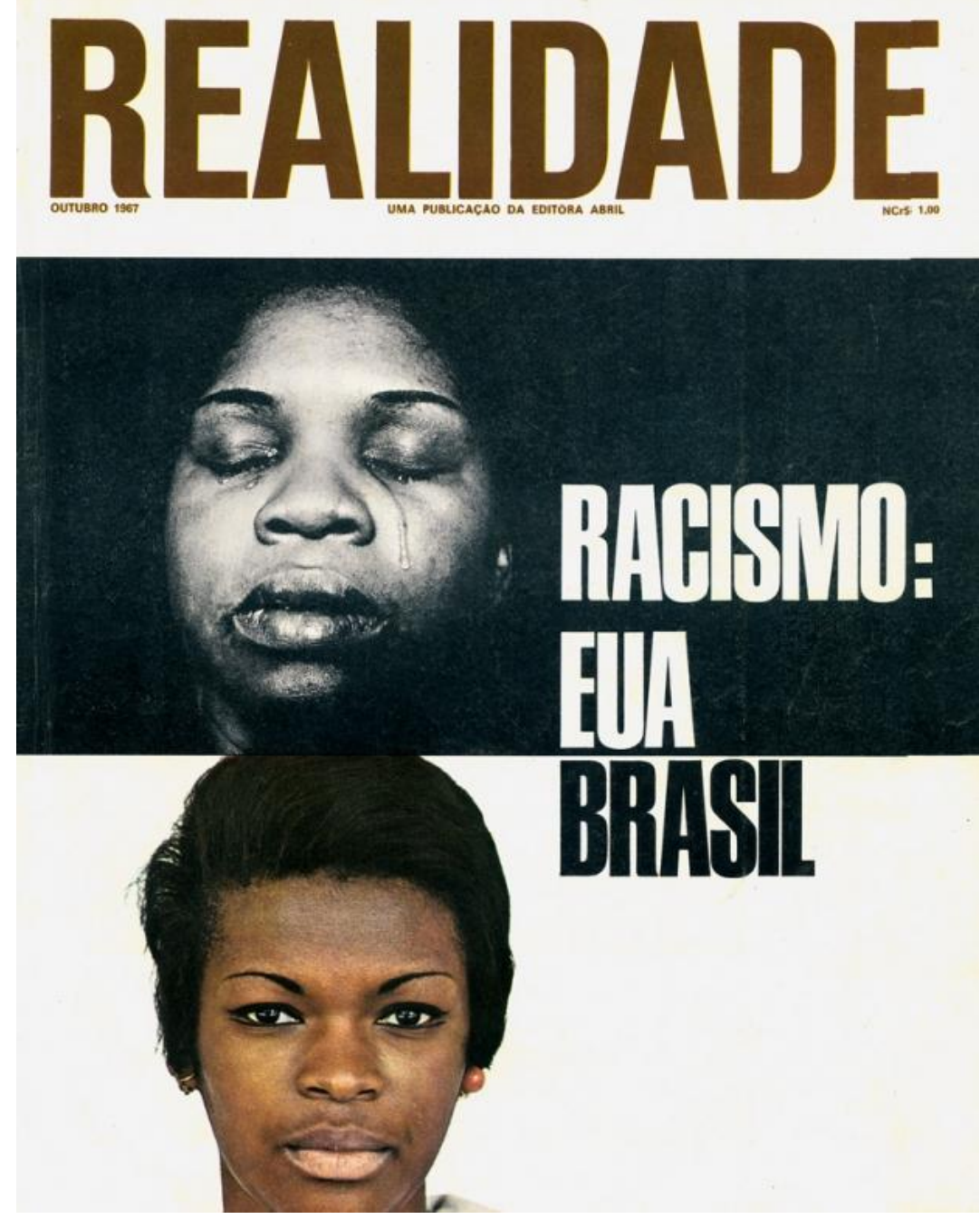

Fonte: Revista Realidade (1967) 
Figura 8 - Matéria de Capa da Revista Realidade no 19, outubro de 1967
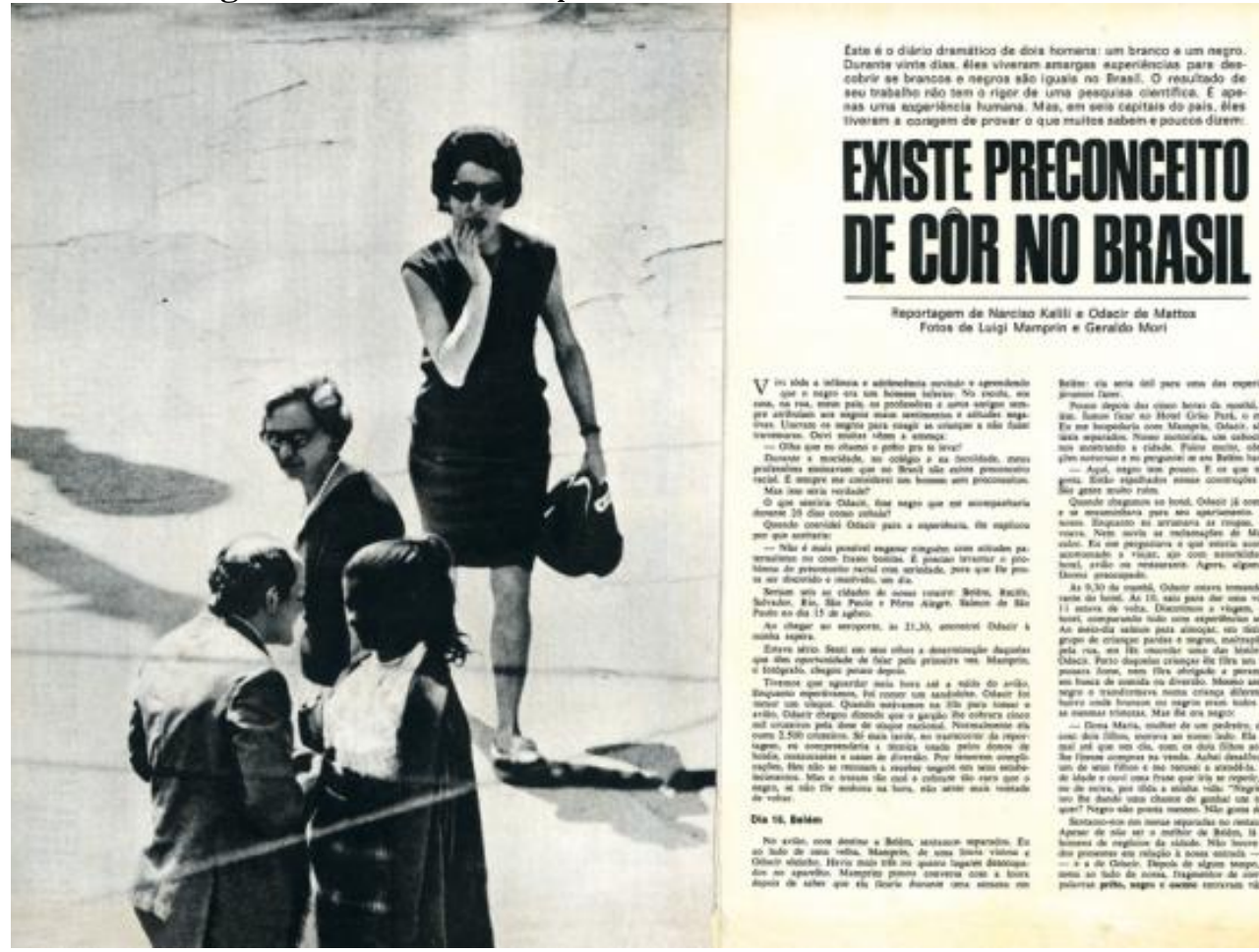

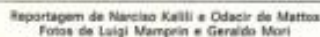
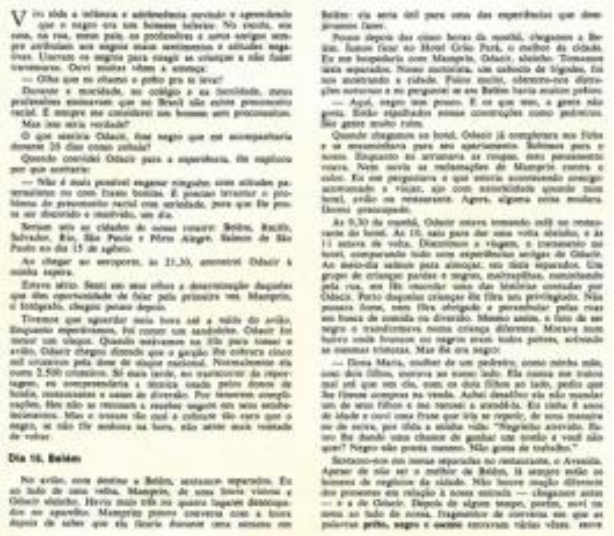

Fonte: Revista Realidade (1967)

No interior da reportagem está reproduzida a capa da referida edição de Realidade (Figura 7) e em outra seção da revista, editoria "Salada", várias capas da própria TRIP aparecem reproduzidas (TRIP, 2014, p. 38 - 39), em ordem cronológica, sob o título "Black is beautiful", indicando personagens negros que as protagonizaram, fazendo o mesmo movimento imagético presente na página do editorial de TPM $(2014$, p. 6), do qual já se falou neste artigo, em outro momento. Ambas as edições de TRIP e TPM compartilham também, por exemplo, de uma mesma enquete de página dupla, "Qual a sua cor?", respondida pelos leitores das revistas e sintetizada num mosaico de selfies repletos de legendas para a questão.

Neste circuito, o acionamento do tema pelo acontecimento que virá - o 13 de maio pergunta jornalisticamente sobre um "mito fundador" - do evento e do discurso - e joga luz sobre ele por uma temática específica - o racismo -, atualizando-a. Como diz Ricouer (2007, p. 60),

[...] não há efetuação ritual sem a evocação de um mito que orienta a lembrança para o que é digno de ser comemorado. As comemorações são, assim, espécies de evocações, no sentido de reatualização, eventos fundadores apoiados pelo "chamado" a lembrar-se que soleniza a cerimônia. 
As edições temáticas de TRIP e TPM de abril de 2014 evocam um mito naturalizado e lançam sobre ele fragmentos temáticos que dizem respeito não apenas a conteúdos propriamente ditos, mas a rotinas editoriais historicamente elaboradas, qualificadas de acordo com questões institucionais e discursivas e potencialmente - voltadas a - críticas. Elaboram, com isso, uma cerimônia própria para o acontecimento que se tematiza e afirmam uma comemoração pela solenidade do incômodo e da diferença. Não apenas buscam questionar o significado de um ritual cultural, mas também celebrar um posicionamento, afirmando-se, perante a um mercado editorial e a um público leitor, como "Outras". TRIP e TPM, como instituições, acabam, elas mesmas, entrando em um (outro) jogo da memória, tentando sobre ele operar de forma autorizada, reforçando seus valores. Afinal, “[...] a memória representada na comemoração aparece dessa forma ligada à imaginação, voltada para escolhas da instituição que não dizem da mimese, mas do imaginário que a instituição se baseia e pretende confirmar [...]" (FRANÇA, 2011, p. 26).

As pautas e o "todo pela parte" que elas ensejam - seja nas edições em separado, seja nas edições em diálogo ou tensão - constroem um circuito cujo fim e o começo não podem ser definidos, mas cujo conjunto, pelas interações promovidas, tem no horizonte uma alteridade social e editorial. Tal indeterminação relacional (fenômeno abarcado pelas duas edições e coberturas) reflete as determinações que envolvem a leitura sobre o tema escolhido e apontam para faces da complexidade do acontecimento tratado em revistas jornalísticas e sua diferente temporalização.

No discurso (pela interpretação) e na atualização (pela noticiabilidade), o caso do racismo e suas facetas, naturalizadas, mostra como o jornalismo torna comum, também, por um produto, uma maneira de se ler o mundo, contribuindo para os outros circuitos que o habitam, dos quais já não se pode dizer quando começam ou terminam, mas como se entrecruzam, social e midiaticamente. Podendo a crítica ser um elemento tanto do mundo quanto do (ao) próprio jornalismo que sobre ele se faz.

\section{Referências}

ANTUNES, Elton. Videntes imprevidentes: temporalidade e modos de construção do sentido de atualidade em jornais impressos diários. 2007. Tese (Doutorado em Comunicação e Cultura Contemporâneas) - Programa de Pós-Graduação em Comunicação e Cultura Contemporâneas, Universidade Federal da Bahia, Salvador, 2007. 
BARBOSA, Marialva Carlos. O presente e o passado como processo comunicacional. Matrizes, São Paulo, v. 5, n. 2, p. 145-155, 2012.

BARBOSA, Marialva Carlos. Meios de comunicação, memória e tempo: a construção da redescoberta do Brasil. In: PEREIRA, Carlos Alberto M.; HERSCHMANN, Micael (Org.). Mídia, memória e celebridades: estratégias narrativas em contextos de alta visibilidade. Rio de Janeiro: e-papers, 2003. p. 112-134.

BENETTI, Márcia; STORCH, Laura; FINATTO JUNIOR, Paulo R. Jornalismo de revista, metaacontecimento e dispositivo de autoridade. In: LEAL, Bruno Souza; ANTUNES, Elton; VAZ, Paulo Bernardo (Org.). Jornalismo e acontecimento: percursos metodológicos. v. 2. Florianópolis: Insular, 2011. p. 55-78.

BERGER, Christa; TAVARES, Frederico de Mello Brandão. Tipologias do acontecimento jornalístico. In: BENETTI, Márcia Benetti; FONSECA, Virgínia. (Org.). Jornalismo e acontecimento: mapeamentos críticos. Florianópolis: Insular, 2010. v. 1 , p. 121-142.

CHARAUDEAU, Patrick. Discurso das mídias. São Paulo: Contexto, 2006.

DESIGNART Blog. The Anatomy of Design: uncovering the Pictorial influences of graphic design. 2012. Disponível em: <https://letmtry.wordpress.com/2012/11/06/the-anatomyof-design/>. Acesso em: 18 jul. 2014.

FRANÇA, Renné. 40 Anos em revista: representações e memória social nas capas de Veja. 2011. Tese (Doutorado em Comunicação Social) - Programa de Pós-Graduação em Comunicação Social, Universidade Federal de Minas Gerais, Belo Horizonte, 2011.

FRANCISCATO, Carlos E. A fabricação do presente: como o jornalismo reformulou a experiência do tempo nas sociedades ocidentais. São Cristóvão: Editora Universidade Federal de Sergipe, 2005.

FRANCISCATO, Carlos E. A atualidade no jornalismo. In: FAUSTO NETO, Antônio et al. (Org.). Práticas midiáticas e espaço público. Porto Alegre: EDIPUCRS, 2001. p. 261-289.

HALBWACHS, Maurice. A memória coletiva. São Paulo: Vértice. 1990.

HIRSZMAN, Maria Lafayette Aureliano. Entre o tipo e o sujeito: os retratos de escravos de Cristiano Jr. 2011. Dissertação (Mestrado em Artes) - Programa de Pós-Graduação em Artes, Universidade de São Paulo, São Paulo, 2011.

KOSIK, Karel. Dialética do concreto. Rio de Janeiro: Paz e Terra, 2010.

MUNANGA, Kabengele. Mestiçagem e experiências interculturais no Brasil. In: SCHWARCZ, Lilia Moritz; REIS, Letícia V. de Sousa (Org.). Negras imagens. São Paulo: Edusp, 1996. p. 179-193.

PÊCHEUX, Michel. 0 discurso: estrutura ou acontecimento. Campinas: Pontes, 1990. 
RASSI, Amanda P. Do acontecimento histórico ao acontecimento discursivo: uma análise da Marcha das Vadias. Revista de História da UEG, Porangatu, v. 1, p. 43-63, 2012.

REVISTA REALIDADE. São Paulo, v. 2, n. 10, edição 19, out. 1967.

REVISTA TPM. São Paulo, v. 13, n. 4, edição 141, abr. 2014.

REVISTA TRIP. São Paulo, v. 28, n. 4, edição 231, abr. 2014.

RICOEUR, Paul. A memória, a história e o esquecimento. Campinas: Unicamp, 2007.

SCHWARCZ, Lilia M. Ser peça, ser coisa: definições e especificidades da escravidão no Brasil. In: SCHWARCZ, Lilia Moritz; REIS, Letícia V. de Sousa (Org.). Negras imagens. São Paulo: Edusp, 1996. p. 11-29.

SILVERTONE, Roger. Por que estudar a mídia? São Paulo: Record, 2002.

TAVARES, Frederico de Mello Brandão. Revista e identidade editorial: mutações e construções de si e de um mesmo. In: TAVARES, Frederico de Mello Brandão Tavares; SCHWAAB Reges Toni. (Org.). A revista e seu jornalismo. Porto Alegre: Penso, 2013. p. 7692.

TAVARES, Frederico de Mello Brandão. Ser revista e viver bem: um estudo de jornalismo a partir de Vida Simples. 2011. Tese (Doutorado em Ciências da Comunicação) - Programa de Pós-Graduação em Ciências da Comunicação, Universidade Vale do Rio Dos Sinos, São Leopoldo, 2011.

TAVARES, Frederico de Mello Brandão. Temas que acontecem: operações entre jornalismo de revista e qualidade de vida. Eco Pós, Rio de Janeiro, v. 12, p. 87-101, 2009.

TITAN JUNIOR, Samuel V. O romance e a revista. As "Memórias póstumas de Brás Cubas" na "Revista Brasileira". Serrote, São Paulo, v. 1, p. 144-149, 2009.

VEYNE, Paul. Como se escreve a história: Foucault revoluciona a história. Brasília: Universidade de Brasília, 1998.

WERTSCH, James. Voices of collective remembering. Cambridge: Cambridge University Press, 2002.

ZELIZER, Barbie. Why memory's work on journalism does not reflect journalism's work on memory. Memory Studies, Los Angeles, v. 1. n. 1. p. 79-87, Jan. 2008. 


\title{
Anticipating May 13: thematic issues, current affairs and memory in TRIP and TPM circuit
}

\begin{abstract}
In April 2014, TRIP and TPM Brazilian magazines published a thematic issue under the same base title - "Being a blackman / a blackwoman in Brazil is $f^{*}$ of" and established an editorial dialog from a temporal hook: the May 13, a day that celebrates the abolition of slavery in the country. One month in advance and from structured journalistic coverages by means of specific content, either in contact or not, these issues anticipated the provided event, ending it with a "totality" of agendas driven by sections, thus provoking a circuit before the "moment of the event", updating it as a theme and indicating its meanings. In this context, this paper notes the relations present in journalistic facts even when they do not start from a factual coverage. Having as object the above-mentioned TRIP and TPM magazines, I try to go through the intersections caused by the theming of the issues and thereby understand the affectations and/ or "determinations" that appear in this scope.
\end{abstract}

\section{Keywords}

Memory. Current affairs. Editing. TRIP magazine. TPM magazine.

Recebido em 16/10/2015

Aceito em 03/01/2016 